\title{
Antibody affinity: immunogenetic aspects and relationship to immune complex disease
}

\author{
M. W. STEWARD \\ Immunology Unit, Department of Medical Microbiology, London School of Hygiene and Tropical Medicine, \\ London
}

It is now widely accepted that the immune response is under a variety of genetic controls which, in several instances, are linked to the major histocompatibility locus (McDevitt and Benacerraf, 1969; Benacerraf and McDevitt, 1972; Benacerraf and Katz, 1975). The functional expression of such autosomal-dominant genetic control is mediated through the co-operative interactions of $B$ and $T$ lymphocytes and macrophages. In addition, a further aspect of the genetic control of the immune response has been described by Biozzi and his coworkers (Biozzi et al., 1968) in which the characteristic of 'general immune responsiveness' is polygenically controlled by a group of about 10 independent loci. The control of this characteristic appears to be antigen non-specific and to be expressed primarily at the level of the macrophage. More recently, however, evidence has been accumulating which indicates that there is an additional genetically-controlled parameter of the immune response, that of the quality or affinity of antibody. In this paper the evidence for the genetic control of antibody affinity and its possible relationship to the development of immune complex disease will be discussed.

\section{Evidence for genetic control of antibody affinity}

Although strain-related variations in the fine specificity of antibodies to a variety of antigens in mice, guinea-pigs, and rats have been recognised by workers in several laboratories for some time (for example, Yoshida et al., 1970; Paul et al., 1970), direct evidence for the genetic control of antibody affinity has only recently become available. The demonstration of consistent strain-related variations in mice of the affinity of antibody produced to human serum albumin (HSA), transferrin (HST), the DNP hapten, and streptococcal carbohydrate injected in saline (Soothill and Steward, 1971; Petty et al., 1972; and unpublished observations) was the first indication that affinity was genetically determined.

However, such strain-related differences were not observed when the antigen was administered in complete Freund's adjuvant (Soothill and Steward, 1971). Subsequently breeding studies were performed with inbred strains of mice producing either high or? low affinity antibody to HSA or HST injected incu saline. Analysis of the affinity of antibody produced $\omega$ in the parents, $F_{1}$ hybrids, and backcrosseshas demonstrated that antibody affinity is under $\vec{\sim}$ polygenic control. The mean affinity value in the $F_{1}$ O hybrids of a high-affinity strain and a low-affinity strain was intermediate between the mean values of the two parental strains. In the backcrosses segre gation of affinity values was observed, which was consistent with some form of genetic control. Thus the distribution of affinity values in the $\left(F_{1} \times\right.$ high affinity parent) backcrosses was not significangy different from that of the high affinity parents and the distribution of affinity values in the $\left(F_{1} \times\right.$ lixo affinity parent) backcrosses was not significantlys different from that of the low affinity parents Antibody levels, however, did not show the same trend as observed for affinity and the two values were not correlated.

These results suggest that affinity and antibody levels are under independent genetic control (Stewar and Petty, 1976). Confirmation has been obtained by a different approach using a selective breeding procedure in which mice were selectively bred on the basis of the affinity of antibody they produce. In this. way two lines of mice have been generated-on: producing high and the other low affinity antibody to protein antigens injected in saline. Antibody levels in these two lines were not correlated with antibod? affinity (Katz and Steward, 1975). The selective breeding procedure resulted in a gradual separation. of the two lines of mice on the basis of antibodo affinity, which suggests that the control of affinity is polygenic. The data on antibody affinity in these mice at generations 8,9 , and 10 are shown in Fig. $1_{\sigma}^{\omega}$ Interestingly, these mice have similar macrophage clearance function (Reinhardt and Steward, 1979) in contrast to other inbred mouse strains where affinity differences were related to differences in macrophage clearance function (Morgan and Soothill, 1975) 


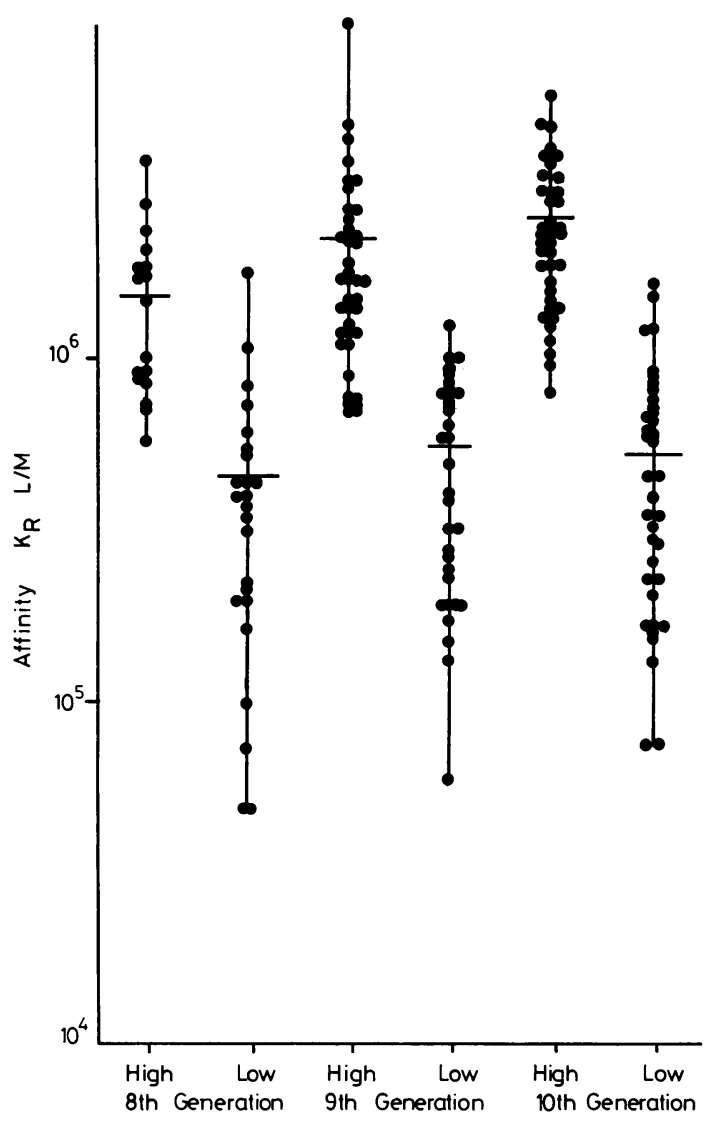

Fig. 1 Genetic selection by antibody affinity. Antibody affinity values in high and low affinity line mice of generations 8,9 , and 10 .

In addition, the genetically selected mice had similar H-2 histocompatibility antigens (Steward et al., 1979).

Further evidence in support of the independent genetic control of antibody levels and affinity was derived from experiments with Biozzi mice which had been selectively bred into two lines-one producing high levels of antibody to heterologous erythrocytes and the other low levels of antibody. The high responders produced high levels of antibody to a broad range of antigens, whereas the low responders produced low levels of antibody. The affinity of antibody to HSA injected in saline was, however, the same in both high and low responders (Katz and Steward, 1976). Recent work from another laboratory (Kim and Siskind, 1977; 1978) has also demonstrated the genetic control of antibody affinity which is exerted independently of the control of antibody levels and is not linked to the major histocompatibility complex.
Relationship of antibody affinity to immune complex disease

After extensive laboratory investigations of the acute and chronic serum sickness models in rabbits it is now widely accepted that there is a relationship between the presence of circulating immune complexes and the development of chronic glomerulonephritis (see Cochrane and Koffler, 1973, for review). Furthermore, several factors are clearly involved in the production, persistence in the circulation, and subsequent tissue localisation of immune complexes including the amount, affinity, quality, and immunoglobulin class of antibody; the size and antibody: antigen ratio of the complexes; the reticuloendothelial function of the host; and vascular permeability considerations. In naturally-occurring immune complex disease both the level and the affinity of the antibody response are probably of major importance, particularly since low affinity antibody is poor at immune elimination of antigen (Alpers et al., 1972).

Since the primary function of antibody is to combine with and eliminate antigen, then failure to achieve this is likely to result in the persistence of antigen and, under certain circumstances, the presence of antigen-excess immune complexes in the circulation. Immune complexes formed in antigen excess are thought to persist in the circulation and to be deposited in, for example, the renal glomerulus. Thus in infections with high antigen load even an immune response with high levels of high affinity antibody may result in the production of injurious complexes. When antigen is not so abundant an immune response of low affinity antibody will fail to eliminate the antigen, and this will favour the production, persistence, and subsequent tissue localisation of antigen-excess immune complexes.

Several lines of evidence support the view that antibody affinity has an important role in circulating immune complex disease.

(1) Inbred strains of mice vary in their susceptibility to chronic immune complex disease after infection with lymphocytic choriomeningitis virus (Oldstone and Dixon, 1969). Some (for example, $\mathrm{A} / \mathrm{Jax} \mathrm{C} 3 \mathrm{H}$ ) do not develop chronic disease whereas others develop chronic immune complex disease (for example, $\mathrm{B}_{10} \mathrm{D}_{2}$ new, $\left.\mathrm{SWR} / \mathrm{J}\right)$, indicating a genetically-controlled variation in susceptibility to disease. When mice from these strains were immunised with protein and hapten antigens in saline animals from the strains which were susceptible to LCM-induced immune complex disease $\left(\mathrm{B}_{10} \mathrm{D}_{2}\right.$ new and $S W R / J)$ produced antibody to the range of antigens which had a consistently lower affinity than that produced by the strains not developing chronic 
disease (A/Jax and C3H)(Soothill and Steward, 1971; Petty et al., 1972). In both active and passive immune elimination experiments low affinity antibody was less effective than high affinity antibody (Alpers et al., 1972).

(2) New Zealand Black $\times$ New Zealand White $F_{1}$ hybrid mice spontaneously develop chronic immune complex disease in which immune complexes of dsDNA- anti-dsDNA are deposited in the renal glomeruli; the disease is more severe, and occurs earlier in females than in males. The avidity of the anti-dsDNA in these mice was measured and compared with the anti-dsDNA present in exbreeding female $\mathrm{A} / \mathrm{Jax}$ mice (a high affinity strain) which do not develop such immune complex disease. The results showed that the avidity of anti-dsDNA in the female NZB/W mice was lower than that in males and the anti-dsDNA in female A/Jax mice was of higher avidity than that in both NZB/W females and males (Steward et al., 1975). The avidity of anti-dsDNA in the sera of patients with human systemic lupus erythematosus has been measured by a dissociation assay (Steward et al., 1974). These studies revealed that in individuals with renal lupus the avidity of anti-dsDNA antibody was lower than that present in sera of individuals with no renal involvement. Workers in other laboratories have measured anti-dsDNA avidity by other methods. The results of Winfield et al. (1977) confirm our observations whereas those of Gershwin and Steinberg (1974) and Leon et al. (1976) do not. These differences may have arisen as a result of methodological variation (Griffiths et al., 1978).

(3) Inbred mice of high (A/Jax) and low (SWR/J) affinity strains have been injected with Trypanosoma bruce $i$ and the incidence of glomerular deposition of C3 and IgG and the development of a nephrotic syndrome investigated (Soothill et al., 1975). The results of these experiments show that the 'low affinity' mice (SWR/J) developed more severe renal damage than did the 'high affinity' mice (A/Jax). This data is therefore consistent with the hypothesis that development of chronic immune complex disease is associated with a genetically-determined low affinity antibody response.

(4) Work on the induction of chronic serum sickness in rabbits by the daily injection of heterologous serum proteins has shown that susceptibility to the development of chronic disease was associated with the presence of non-precipitating antibody in the serum and poor elimination of antigen (Pincus et al., 1968). We have shown that low affinity antibody is poor at eliminating antigen (Alpers et al., 1972) and that low affinity antibody to a range of antigens was produced by mice prone to LCM-induced immune complex disease (see above).
Accordingly, experiments are now in progress t产 determine whether the genetically-controlleg characteristic of low affinity antibody production $t \overline{8}$ human serum albumin predisposes to the development of chronic immune complex disease. The following is a preliminary account of these experiments.

Mice have been injected repeatedly with huma serum albumin in a manner analogous to the experiments in rabbits of Dixon et al. (1961) ang Pincus et al. (1968) in order to study the developmerift of chronic immune complex disease. Inbred mice with the characteristic of either low affinity ant $\overrightarrow{\mathrm{t}}$ HSA antibody production (SWR/J) or high affinify anti-HSA production (Simpson) were used in of group of experiments, and low and high affinity line mice generated by selective breeding (see aboves) were used in a second group of experiments. $\vec{\omega}$

In both groups of experiments mice were injected repeatedly with HSA in saline in doses calculated, $\overrightarrow{0}$ the basis of antibody levels determined during the experiment, to maintain the presence of slight antigen-excess immune complexes in the circulation. During the course of the experiment levels of circulating HSA-anti-HSA immune complexes werge determined by ammonium sulphate globulin pre cipitation of serum at 2 and 24 hours after the injection of ${ }^{125} \mathrm{I}$-labelled HSA. In addition, re्gु|

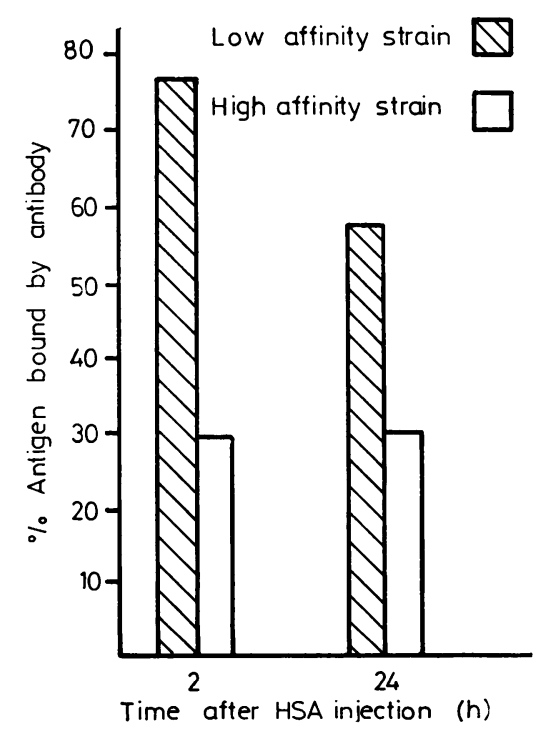

Fig. 2 Levels of circulating ${ }^{125} I-H S A$-anti-HSA immune complexes 2 and 24 hours after injection of ${ }^{125}$ I-HSA measured by ammonium sulphate precipitation $\stackrel{\text { ? }}{+}$ in low $(S W R / J)$ and high (Simpson) affinity inbred mice 0 which had been injected with HSA repeatedly for 6 week? 


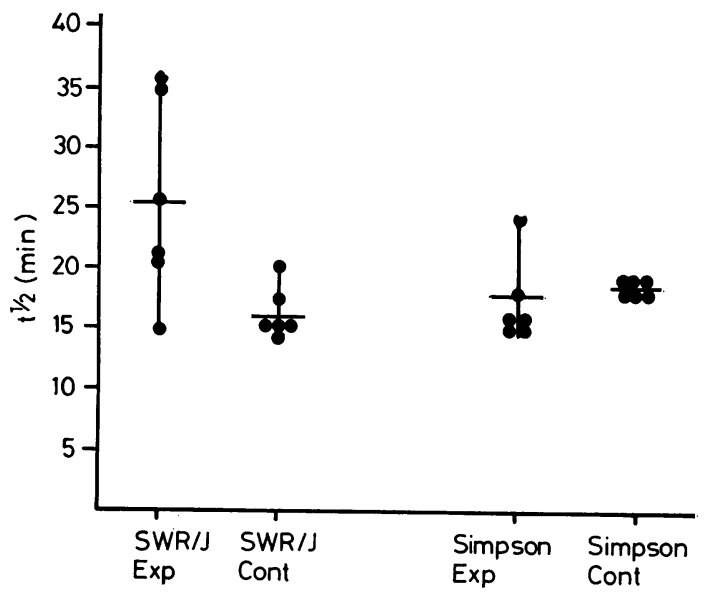

Fig. 3 Glomerular filtration rate in low $(S W R / J)$ and high (Simpson) affinity inbred mice after 5 weeks of injections of $H S A$ assessed by clearance of $\left[{ }^{51} C r\right]-E D T A$.

function was assessed by measurement of the clearance of $\left[{ }^{51} \mathrm{Cr}\right]-\mathrm{EDTA}$ (Knight et al., 1977). Cryostat sections of kidneys were stained with FITCconjugated anti-mouse immunoglobulin and FITCconjugated anti-human serum albumin.

After 6 weeks of injections low affinity (SWR/J) mice had higher levels of antibody-bound ${ }^{125}$ I-HSA (that is, immune complex) than did mice of the high affinity strain (Simpson) both at 2 and 24 hours after injection of the antigen (Fig. 2). There was also evidence from $\left[{ }^{51} \mathrm{Cr}\right]-$ EDTA clearance measurements that renal function in the low affinity mice was impaired compared with control mice of the same strain and compared with high affinity mice (Fig. 3). At the end of the study only kidneys of the surviving mice of the injected low affinity strain had deposition of mouse immunoglobulin and antigen as demonstrated by immunofluorescence. These preliminary experiments, therefore, indicate that inbred mice with the characteristic of low affinity antibody production have more evidence of chronic immune complex disease than mice that produce higher affinity antibody.

A similar experimental approach has been used to study the role of antibody affinity in the induction of chronic serum sickness in the selectively bred high and low affinity line mice that produce similar antibody levels to protein antigen, have similar histocompatibility antigens and macrophage clearance function, but differ only in antibody affinity. The results of these experiments are to be reported in detail elsewhere (Steward et al., 1979), but I briefly describe them here.
After repeated injections of HSA in saline both high and low affinity lines of mice had evidence of immune complex disease as indicated by the presence of circulating immune complexes and the deposition of mouse immunoglobulin and the antigen in the glomeruli. There were, however, differences in the pattern and severity of the disease between the two lines. As shown by a pronounced reduction in glomerular filtration rate, more low than high affinity line mice had renal impairment. There were also differences in renal disease as revealed by fluorescence microscopy. Kidneys from low affinity line mice showed intense fluorescent staining with both fluorescent anti-mouse immunoglobulin and anti-HSA, which was localised predominantly on the basement membrane. Kidneys from high affinity line mice, on the other hand, had less intense fluorescence staining with these reagents and it was localised predominantly in the mesangium. After eluting immune complexes from kidneys of both lines of mice and subsequently isolating the anti-HSA antibody component, binding studies with ${ }^{125}$ I-HSA showed that four times as much antibody was eluted from low-line kidneys than from high-line kidneys. These results may be interpreted in the light of the hypothesis of Germuth and Rodriguez (1973) that small soluble complexes (class I) are localised on the glomerular basement membrane, whereas larger, slightly less soluble complexes (class II) are localised in the subendothelial-mesangial region. Therefore the basement membrane localisation of complexes seen in low affinity line mice can be viewed as arising from the deposition of small, soluble complexes perhaps comprised of low affinity antibody and antigen, whereas the mesangial localisation seen in high affinity line mice may result from the deposition of larger complexes with higher affinity antibody. The affinity characteristics of antibody localised in chronic immune complex disease in mice is presently being actively investigated.

\section{Conclusions}

It is now well established that antibody affinity is a multi-genetically controlled parameter of the immune response and that such control is exerted by genetic mechanisms that are independent of those controlling antibody levels. Furthermore, the control of affinity is not linked to the major histocompatibility complex. The immunopathological significance of the genetic control of antibody affinity is suggested by the association of the production of low affinity antibody with both the development of chronic immune complex disease after deliberate infection with LCM virus and $T$. bruce $i$ and the spontaneous immune complex disease 
of NZB/W mice. Furthermore, repeated administration of HSA induced a more severe chronic immune complex disease in both inbred mice and selectively bred mice that have the characteristic of low affinity antibody production compared with mice producing high affinity antibody. A low affinity antibody response is likely to be poor at eliminating antigen and this favours the production, persistence in the circulation, and subsequent tissue localisation of antigen-excess immune complexes.

Part of the work described here was supported by the Wellcome Trust.

\section{References}

Alpers, J. H., Steward, M. W., and Soothill, J. F. (1972). Differences in immune elimination in inbred mice: the role of low affinity antibody. Clinical and Experimcntal Immunology, 12, 121-132.

Benacerraf, B., and Katz, D. H. (1975). The nature and function of histocompatibility-linked immune response genes. In Immunogenetics and Immunodeficiency, edited by B. Benacerraf, p. 117-177. M.T.P. Press, Lancaster.

Benacerraf, B., and McDevitt, H. O. (1972). Histocompatibility-linked immune response genes. Science, 175, 273-279.

Biozzi, G., Stiffel, C., Mouton, D., Bouthillier, Y., and Decreusefond, C. (1968). Sélection artificielle pour la production d'anticorps chez la souris. Annales de l'Institut Pasteur, 115, 965-967.

Cochrane, C. G., and Koffler, D. (1973). Immune complex disease in experimental animals and man. Advances in Immunology, 16, 185-264.

Dixon, F. J., Feldman, J. D., and Vasquez, J. J. (1961). Experimental glomerulonephritis: the pathogenesis of a laboratory model resembling the spectrum of human glomerulonephritis. Journal of Experimental Medicine, 113, 899-920.

Germuth, F. G., and Rodriguez, E. (1973). Immunopathology of the Renal Glomerulus. Little, Brown and Company, Boston, Mass.

Gershwin, M. E., and Steinberg, A. D. (1974). Qualitative characteristics of anti-DNA antibodies in lupus nephritis. Arthritis and Rheumatism, 17, 947-954.

Griffiths, G. D., Olsen, I., and Steward, M. W. (1978). Comparison of three methods used for the measurement of the avidity of antibody to DNA. Journal of Immunological Methods, 21, 143-157.

Katz, F. E., and Steward, M. W. (1975). The genetic control of antibody affinity in mice. Immunology, 29, 543-548.

Katz, F. E., and Steward, M. W. (1976). Studies on the genetic control of antibody affinity: The independent control of antibody levels and affinity in Biozzi mice. Journal of Immunology, 117, 477-479.

Kim, Y. T., and Siskind, G. W. (1977). Studies on the control of antibody synthesis. X. Selective breeding of rats for the production of high-affinity antibody.

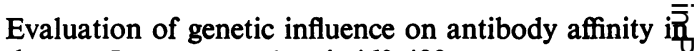
the rat. Immunogenetics, 4, 463-480.

Kim, Y. T., and Siskind, G. W. (1978). Studies on the control of antibody synthesis. XII. Genetic influences on antibody affinity. Immunology, 34, 669-678.

Knight, J. G., Adams, D. D., and Purves, H. D. (1977f? The genetic contribution of the NZB mouse to the renal disease of the NZB $\times$ NZW hybrid. Clinical ari Experimental Immunology, 28, 352-358.

Leon, S. A., Green, A., Ehrlich, G. E., Poland, M., an Shapiro, B. (1976). Avidity of antibodies in SLES3 relation to severity of renal involvement. (Abstract.) Arthritis and Rheumatism, 19, 806.

McDevitt, H. O., and Benacerraf, B. (1969). Genetict control of specific immune responses. Advances Immunology, 11, 31-74.

Morgan, A. G., and Soothill, J. F. (1975). Relationshị between macrophage clearance of PVP and affinity of anti-protein antibody response in inbred mouse strains. Nature (London), 254, 711-712.

Oldstone, M. B. A., and Dixon, F. J. (1969). Pathogenesis of chronic disease associated with persistent lymphou cytic choriomeninigitis viral infection. Journal of Experimental Medicine, 129, 483-505.

Paul, W. E., Yoshida, T., and Benacerraf, B. (1970). Genetic control of the specificity of anti-DNP antw bodies. II. Differences in the specificity of anti-DNE antibody produced by several inbred strains of mice Journal of Immunology, 105, 314-321.

Petty, R. E., Steward, M. W., and Soothill, J. F. (19\$2 24 The heterogeneity of antibody affinity in inbred rice and its possible immunopathologic significance. Clinical and Experimental Immunology, 12, 231-241응

Pincus, T., Haberkern, R., and Christian, C. L. (1968 Experimental chronic glomerulitis. Journal of Expere mental Medicine, 127, 819-832.

Reinhardt, M. C., and Steward, M. W. (1979). Antibodg affinity and clearance function studies in high an low affinity mice. The effect of protein deficiencys Immunology. In press.

Soothill, J. F., Smith, M. D., and Morgan, A. G. (1975 Immunodeficiency and the allergic effects of parasitic infection. In Pathogenic Processes in Parasit Infections (British Society for Parasitology, Symposia Vol. 13), edited by A. E. R. Taylor and R. Mülleğ vol. 13, p. 59. Blackwell, Oxford.

Soothill, J. F., and Steward, M. W. (1971). The immuno pathological significance of the heterogeneity of antibody affinity. Clinical and Experimental Immunos $\log y$, 9, 193-199.

Steward, M. W. (1979). Chronic immune comple disease in mice. The role of antibody affinity. Clinicab and Experimental Immunology. In press.

Steward, M. W., Glass, D. N., Maini, R. N., and Scotn J. T. (1974). Role of low avidity antibody to native DNA in human and murine lupus syndromes. Journglf of Rheumatology, 1, Supplement 1, 41. (Abstract.)

Steward, M. W., Katz, F. E., and West, N. J. (1975). The role of low affinity antibody in immune comples disease; the quantity of anti-DNA antibodies in NZB/W $F_{1}$ hybrid mice. Clinical and Experimentap Immunology, 21, 121-130. 
Steward, M. W., and Petty, R. E. (1976). Evidence for the genetic control of antibody affinity from breeding studies with inbred mouse strains producing high and low affinity antibody. Immunology, 30, 789-797.

Steward, M. W., Reinhardt, M. C., and Staines, N. A. (1979). The genetic control of antibody affinity. Evidence from breeding studies with mice selectively bred for either high or low affinity antibody production. Immunology, 37, 697-703.

Winfield, J. B., Faiferman, I., and Koffler, D. (1977).
Avidity of anti-DNA antibodies in serum and IgG glomerular eluates from patients with systemic lupus erythematosis. Journal of Clinical Investigation, 59, 90-96.

Yoshida, T., Paul, W. E., and Benacerraf, B. (1970). Genetic control of the specificity of anti-DNP antibodies. I. Differences in the specificity of anti-DNP. antibody produced by mammalian species. Journal of Immunology, 105, 306-313. 